\title{
RNA interference-mediated silencing of aquaporin (AQP)-5 hinders angiogen- esis of colorectal tumor by suppressing the production of vascular endothelial growth factor
}

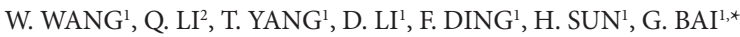 \\ ${ }^{1}$ Department of General Surgery, The First Affiliated Hospital of Jinzhou Medical University, Jinzhou, Liaoning 121001, People's Republic of \\ China; ${ }^{2}$ Department of Internal Medicine, The Third Affiliated Hospital of Jinzhou Medical University, Jinzhou, Liaoning 121001, People's Re- \\ public of China
}

*Correspondence: baiguang69255@163.com

Received October 19, 2016 / Accepted May 17, 2017

\begin{abstract}
Aquaporin (AQP)-5 is an essential member of AQP family involved in the tumorigenesis of various malignant tumors. However, its role in the angiogenesis of colorectal cancer is unclear and requires further investigation. In this study, a pRNA-H1.1 vector containing the short hairpin RNA (shRNA) targeting AQP5 mRNA was constructed to inhibit the endogenous expression of AQP5 in human umbilical vein endothelial cells (HUVECs). We found that the AQP5-silenced HUVECs acquired decreased proliferation, migration and tube formation ability. AQP5 shRNA also inhibited the enzyme activity of matrix metalloprotease (MMP)-9 in HUVECs without affecting the MMP-2. Further, two colorectal cancer cell lines (HT29 and HCT116) stably transfected with scrambled or AQP5 shRNA were established. The expression and secretion of vascular endothelial growth factor (VEGF)-A (a pro-angiogenic factor) in colorectal cancer cells were downregulated by AQP5 shRNA. HUVECs cultured in low-VEGF conditioned media (CM) obtained from cancer cells developed less vessel-like tubes and had decreased proliferation and migration. The growth and angiogenesis of xenograft tumors were suppressed when the endogenous AQP5 in HT29 cells was knocked down. Tumor samples were additionally collected from patients with colorectal cancer to analyze the expression of AQP5. The immunofluorescence data indicated that AQP5 was expressed in both inner cancer areas and CD31-positive vessels. Taken together, our study suggests AQP5 as a novel antiangiogenesis target for colorectal cancer.
\end{abstract}

Key words: aquaporin 5, vascular endothelial growth factor, colorectal cancer, angiogenesis, vascular endothelial cells

Colorectal cancer, one of the most common malignancies, continues to be a major cause of cancer mortality worldwide [1]. Diagnosis and treatment have been investigated and implemented to reduce the mortality of patients with colorectal cancer [2], but more efficient therapy depending on the tumor biology should be investigated to increase the recovery rate and reduce the tumor recurrence.

Metastatic spread has always been a big problem in antitumor therapy. The growth and metastasis of malignant tumors depend on the blood vessels. It is reported that the tumors will be starved to death if the blood vessels don't supply the nutrients $[3,4]$. The growth and proliferation of both primary and metastatic tumors are closely related to neovascularization [5]. Therefore, the inhibition of neovascularization has been suggested as one of the most important anti-tumor therapies for the control of tumorigenesis.
Aquaporins (AQPs) are a family of water channel proteins that regulate water transport across the cell membrane [6]. AQP5 as a critical member of AQP family was first cloned from rat submandibular gland [7], and has been shown to contribute to the progression of various types of malignant tumors [8-12]. Recent studies reveal AQP5 as an oncogene involved in carcinogenesis [13] and suggest it as a novel prognostic biomarker for various types of tumors [14, 15]. Interestingly, an abnormal overexpression of AQP5 has been found in colorectal cancer samples, which is linked to the aggressiveness and metastasis $[15,16]$. AQPs may be involved in the angiogenesis [17], however, whether and how AQP5 affects the angiogenesis of colorectal cancer is still unknown and requires further elucidation.

In the present study, AQP5 short hairpin RNA (shRNA) was applied to inhibit the endogenous expression of AQP5 in 
vascular endothelial cells and colorectal cancer cells. Further, the conditioned media (CM) were obtained from HT29 and HCT116 stably transfected with AQP5 shRNA to incubate human umbilical vein endothelial cells (HUVECs). The cell proliferation, migration and angiogenesis of HUVECs were detected. The basal expression levels of AQP5 in human colorectal carcinoma samples were also analyzed.

\section{Patients and methods}

Patients. Tumor tissues were collected from 9 patients with colorectal cancer at the First Affiliated Hospital of Jinzhou Medical University between December 15, 2016 and January 8,2017 . Written informed consents were provided by the patients, and all procedures were approved by the Research Ethics Board of Jinzhou Medical University. No neoadjuvant therapy was applied before sampling. The clinicopathological parameters were summarized in Supplementary Table 1.

Cell culture, plasmid construction and transfection. The HT29, HCT116 and HUVECs were cultured in Dulbecco's modified Eagle's medium (DMEM; Gibco, Grand Island, NY, USA) with 10\% fetal bovine serum (FBS; Hyclone, Logan, UT, USA) at $37^{\circ} \mathrm{C}$ in a $5 \% \mathrm{CO}_{2}$ humidified environment. Cells were plated in 6-well plates at a density of $1 \times 10^{5}$ per well and cultured at $37^{\circ} \mathrm{C}$ in a $5 \% \mathrm{CO}_{2}$ incubator for $24 \mathrm{~h}$. The specific shRNA of human AQP5 gene (AQP5-shRNA) and nonspecific control (NC) were inserted into pRNA-H1.1 vector (GenScript, Piscataway, NJ, USA). These plasmids were confirmed by DNA sequencing. Then, the AQP5-shRNA plasmid and NC plasmid were transiently transfected into HUVECs by using a Lipofectamine 2000 reagent (Invitrogen, Carlsbad, CA, USA) according to the manufacturer's instructions. G418 (Invitrogen) was used to select HT29 $(100 \mu \mathrm{g} / \mathrm{ml} \mathrm{G} 418)$ and HCT116 cells $(200 \mu \mathrm{g} / \mathrm{ml}$ G418) stably transfected with NC or AQP5 shRNA. Where necessary, $10 \mathrm{ng} / \mathrm{ml}$ recombinant VEGF (Sino Biological Inc. Beijing, China) was added into CM.

Quantitative real-time PCR (qRT-PCR) assay. Total RNAs were obtained by using a RNApure total RNA fast isolation kit (BioTeke, Beijing, China) and the cDNA synthesis was performed via Super M-MLV reverse transcriptase (BioTeke) according to the manufacturer's instructions. The qRT-PCR assay was conducted in Exicycler 96 (Bioneer, Daejeon, Korea) to determine the expression levels of AQP5 in untreated, NC transfected and AQP5-shRNA transfected HUVECs. Moreover, CM from HT29 and HCT116 cell lines which were stably transfected with NC plasmid

Table 1. Primer list for real-time PCR.

\begin{tabular}{ll}
\hline Primer name & Sequence $\left(\mathbf{5}^{\prime}-\mathbf{3}^{\prime}\right)$ \\
\hline AQP5 F & TGGCTGCCATCCTTTACTTCTACC \\
AQP5 R & CCCAGTCCTCGTCAGGCTCATA \\
VEGFA F & CCCACTGAGGAGTCCAACATC \\
VEGFA R & ATTAGACAGCAGCGGGCACC \\
\hline
\end{tabular}

or AQP5-shRNA plasmid were harvested. RT-PCR was conducted to investigate the expression levels of AQP5 and VEGFA. Two pairs of primers (AQP5-F/R and VEGFA-F/R) were designed (Table 1) and the primer of $\beta$-actin-F/R was used as a control throughout all analyses. The reactions were performed in triplicate in $20 \mu \mathrm{l}$ volume containing: $1 \mu \mathrm{l}$ of cDNA, $0.5 \mu \mathrm{l}$ of each primer, $10 \mu \mathrm{l}$ of SYBR GREEN master mix (Solarbio, Beijing, China) and $8 \mu \mathrm{ddd}_{2} \mathrm{O}$. The expression levels were determined via the $2^{-\Delta \Delta C T}$ method [18].

Western blot. The following primary antibodies were used for western blot: AQP5 antibody (1:200; Santa cruz, Santa Cruz, CA, USA), matrix metalloprotease-2 (MMP-2) antibody (1:500; Bioss, Beijing, China), MMP-9 antibody (1:500; Sangon, Shanghai, China) and $\beta$-actin (1:1000; Santa Cruz).

The cell lysates were obtained in RIPA buffer (Beyotime, Beijing, China) containing $1 \%$ phenylmethylsulfonyl fluoride (PMSF) (Beyotime), and the protein concentration was measured using a BCA Protein Assay Kit (Beyotime) according to the manufacturer's instruction. The same amount of protein samples was separated on a $13 \%$ sodium dodecyl sulphate-polyacrylamide gel electrophoresis (SDS-PAGE) and then transferred onto PVDF membranes (Millipore, Bedford, MA, USA). After transfer, the membranes were washed with TTBS buffer for $5 \mathrm{~min}$ and blocked with 5\% skim milk for $1 \mathrm{~h}$, followed by incubation with antibodies. After being washed with TTBS, HRP-labeled Goat AntiMouse IgG $(\mathrm{H}+\mathrm{L})$ (1:5000; Beyotime) was used to incubate the membranes for $45 \mathrm{~min}$ at $37^{\circ} \mathrm{C}$. Finally, the protein blots were visualized by ECL Reagent (7sea biotech, Shanghai, China), and analyzed with the gel imaging system software. $\beta$-actin was used as endogenous control.

3-(4,5-dimethyl-2-thiazolyl)-2,5-diphenyl-2H-tetrazolium bromide (MTT) assay. HUVECs cultured in 96-well plates for different time periods were subjected to MTT assay. Cells were incubated with MTT $(0.5 \mathrm{mg} / \mathrm{ml})$ for $4 \mathrm{~h}$ at $37^{\circ} \mathrm{C}$, and then $200 \mu \mathrm{l}$ dimethylsulfoxide (DMSO; Sigma, St. Louis, MO, USA) was added. The OD values at a wavelength of $490 \mathrm{~nm}$ were measured using a microplate reader (BioTek, Winooski, VT, USA). Each experiment was carried out in quintuplicate.

Scratch assay. Scratch assay was conducted to investigate the migration of HUVECs. Briefly, cells were pretreated with $1 \mu \mathrm{g} / \mathrm{ml}$ Mitomycin C from Streptomyces caespitosus (Sigma) for $1 \mathrm{~h}$ and cultured in serum-free medium. The scratch wound area was created with a sterile $200-\mu$ l pipette tip. Cell migration was photographed at 0,12 and $24 \mathrm{~h}$, respectively.

Gelatin zymography. After transfection for $48 \mathrm{~h}$, the supernatants of HUVECs were collected at $12 \mathrm{~h}$ and $24 \mathrm{~h}$ to detect the activities of MMP-2 and MMP-9. In short, the same amount of samples was separated by $0.1 \%$ gelatin- $10 \%$ SDS-PAGE gel, eluted twice with $2.5 \%$ Triton X-100, and then washed with $50 \mathrm{mM}$ Tris- $\mathrm{HCl}$ buffer $\left(5 \mathrm{mM} \mathrm{CaCl}_{2}, 1 \mu \mathrm{M}\right.$ $\mathrm{ZnCl}_{2}, \mathrm{pH}$ 7.6). Thereafter, the membranes were incubated in $50 \mathrm{mM}$ Tris- $\mathrm{HCl}$ buffer $\left(5 \mathrm{mM} \mathrm{CaCl}_{2}, 1 \mu \mathrm{M} \mathrm{ZnCl}_{2}, 0.02 \%\right.$ 
Brij, 0.2 $\mathrm{M} \mathrm{NaCl}$ ) for $40 \mathrm{~h}$ and then stained with Coomassie blue $(0.05 \%$ Coomassie brilliant blue G-250, 30\% methanol, $10 \%$ acetic acid) for $3 \mathrm{~h}$.

Tube formation assay. HUVECs were plated in 96-well plates coated with Matrigel (BD, Bedford, MA, USA) at a density of $3 \times 10^{3}$ per well, and allowed to grow for $24 \mathrm{~h}$ at $37^{\circ} \mathrm{C}$. The tubes were photographed $(40 \times$ magnification), and their total number was counted. All assays were performed in triplicate.

Enzyme-linked immunosorbent assay (Elisa). The secretory level of VEGFA in cell supernatants was detected with a commercial Elisa Kit for VEGFA (USCN, Wuhan, China) according to the manufacturer's instructions.

Immunofluorescence (IF) assay. The $5-\mu \mathrm{m}$ tumor tissue slices were dewaxed and rehydrated before antigen retrieval. Cells in each group were fixed with $4 \%$ paraformaldehyde for 15 min on glass slides, washed with PBS for three times, and permeabilized with $0.1 \%$ tritonX-100 for $30 \mathrm{~min}$ at room temperature (RT). The tissue slices or cell slides were blocked with goat serum (Solarbio) for $30 \mathrm{~min}$ or $15 \mathrm{~min}$ at RT, respectively. Thereafter, the samples were incubated with VEGFA antibody (1:200; Beyotime), CD31 antibody (1:200; CST, Beverly, MA, USA) or AQP5 antibody (1:200, Abcam, Cambridge MA, UK) at $4^{\circ} \mathrm{C}$ overnight, and then with Cy3-labeled goat anti-rabbit $\operatorname{IgG}(\mathrm{H}+\mathrm{L})$ secondary antibody (1:300; Beyotime), Cy3-labeled goat anti-mouse $\operatorname{IgG}(\mathrm{H}+\mathrm{L})$ antibody (1:200; Beyotime) or fluorescein isothiocyanate (FITC)-labeled goat anti-rabbit $\operatorname{IgG}(\mathrm{H}+\mathrm{L})$ (1:200; Beyotime) over $60 \mathrm{~min}$. Cell nuclei were counterstained with 4,6-diamidino-2-phenylindole (DAPI). Fluorescent imaging was captured with a fluorescence microscope (Olympus, Tokyo, Japan).

Xenograft tumors. Nude mice (BALB/c-nu) were obtained from Vital River Laboratory Animal Technology Co. Ltd (Beijing, China), and were randomly divided into three groups. Control or AQP5 shRNA-transfected HT29 cells $\left(1 \times 10^{7} / 0.2 \mathrm{ml}\right)$ were subcutaneously infected into the armpit of the mice ( $n=6$ per group). The tumor volume was measured at day $9,12,15,18,21,24,27$ and 30 post injection. Then, all mice were sacrificed to collect the xenograft tumors. All animal experiments were carried out under an approved protocol from the Institutional Animal Care and Use Committee of Jinzhou Medical University.

Immunohistochemistry (IHC). IHC was performed to detect the expression of CD31 (an endothelial marker) [19] in xenograft tumors. First, the harvested xenograft tumor samples were embedded in paraffin, then cut into 5 - $\mu$ m sections with a microtome (Leica, Wetzlar, Germany) and placed on glass slides. The sections were deparaffinized in xylene, rehydrated in ethanol, boiled in antigen retrieval buffer for $10 \mathrm{~min}$ and then incubated in $3 \% \mathrm{H}_{2} \mathrm{O}_{2}$ at RT for $15 \mathrm{~min}$. Following several washes in PBS, the sections were incubated with goat serum for $15 \mathrm{~min}$ at RT and then with CD31 antibody (1:50; Santa cruz) at $4{ }^{\circ} \mathrm{C}$ overnight. Thereafter, the slices were rinsed with PBS and incubated with biotin-labeled goat anti-rabbit IgG $(\mathrm{H}+\mathrm{L})$ secondary antibody (1:200; Beyotime) for $30 \mathrm{~min}$ and then with HRP-labeled streptavidin for additional $30 \mathrm{~min}$ at RT in a humidified box. Finally, the slides were visualized by $100 \mu \mathrm{DAB}$ (Solarbio) and counterstained with hematoxylin (Solarbio) for $3 \mathrm{~min}$. Images were captured to analyze the CD31 positive vessels.

Statistical method. All data were analyzed with the Graphpad Prism 6 software (GraphPad, San Diego, CA, USA). The homogeneity of variance was first analyzed, and the significance of difference between two groups was determined with the unpaired Student's t-test. Data from different time points were evaluated by two-way ANOVA, followed by Bonferroni multiple comparison test. All data were presented as means \pm standard deviation (SD), and the differences were considered significant at $\mathrm{p}<0.05$.

\section{Results}

Knockdown of AQP5 inhibits the proliferation, migration and tube formation of HUVECs. AQP5 shRNA was first confirmed to effectively inhibit the endogenous expression of AQP5 in HUVECs (Supplementary Figure 1). Results from MTT assay showed that proliferation of HUVECs was suppressed when AQP5 was downregulated (Figure 1A). AQP5-silenced HUVECs acquired a reduced migration and tube formation capability (Figure 1B-E). Further, AQP5 shRNA inhibited the activity and expression of MMP-9 in HUVECs, but not that of MMP-2 (Figure 1F and G). These results illustrate that AQP5 plays a role in maintaining the growth and angiogenic ability of vascular endothelial cells.

VEGF secreted by colorectal cancer cells promotes the growth and angiogenesis of HUVECs in vitro. HT29 and HCT116 cells stably expressing AQP5 shRNA were first established. A significant down-regulation of AQP5 was observed in these cancer cells (Supplementary Figure 2). Results from qRT-PCR and IF assay showed that the mRNA and protein expression levels of VEGFA in the two cancer cell lines were decreased (Figure 2A-D). The Elisa results indicated that AQP5-silenced HT29 and HCT116 cells secreted less VEGFA into supernatants (Figure 2E and F). Further, HUVECs were incubated in CM collected from NC or AQP5 shRNA-transfected cancer cells and their growth and angiogenic ability were determined. Data from MTT analysis illustrated a decreased proliferation of HUVECs cultured in low-VEGF media (Figure 3A and B). Also, their migration and tube formation capability were inhibited (Figure 3C-F and Figure 4). In addition, HUVECs were cultured in cancer cell CM in presence or absence of $10 \mathrm{ng} /$ $\mathrm{ml}$ recombinant VEGF. We found that addition of VEGF partly restored the impaired migratory and angiogenic ability of HUVECs cultured in low-VEGF media (Figure 5). Collectively, these results suggest that the VEGF secreted by colorectal cancer cells promotes the growth and angiogenesis of HUVECs. 

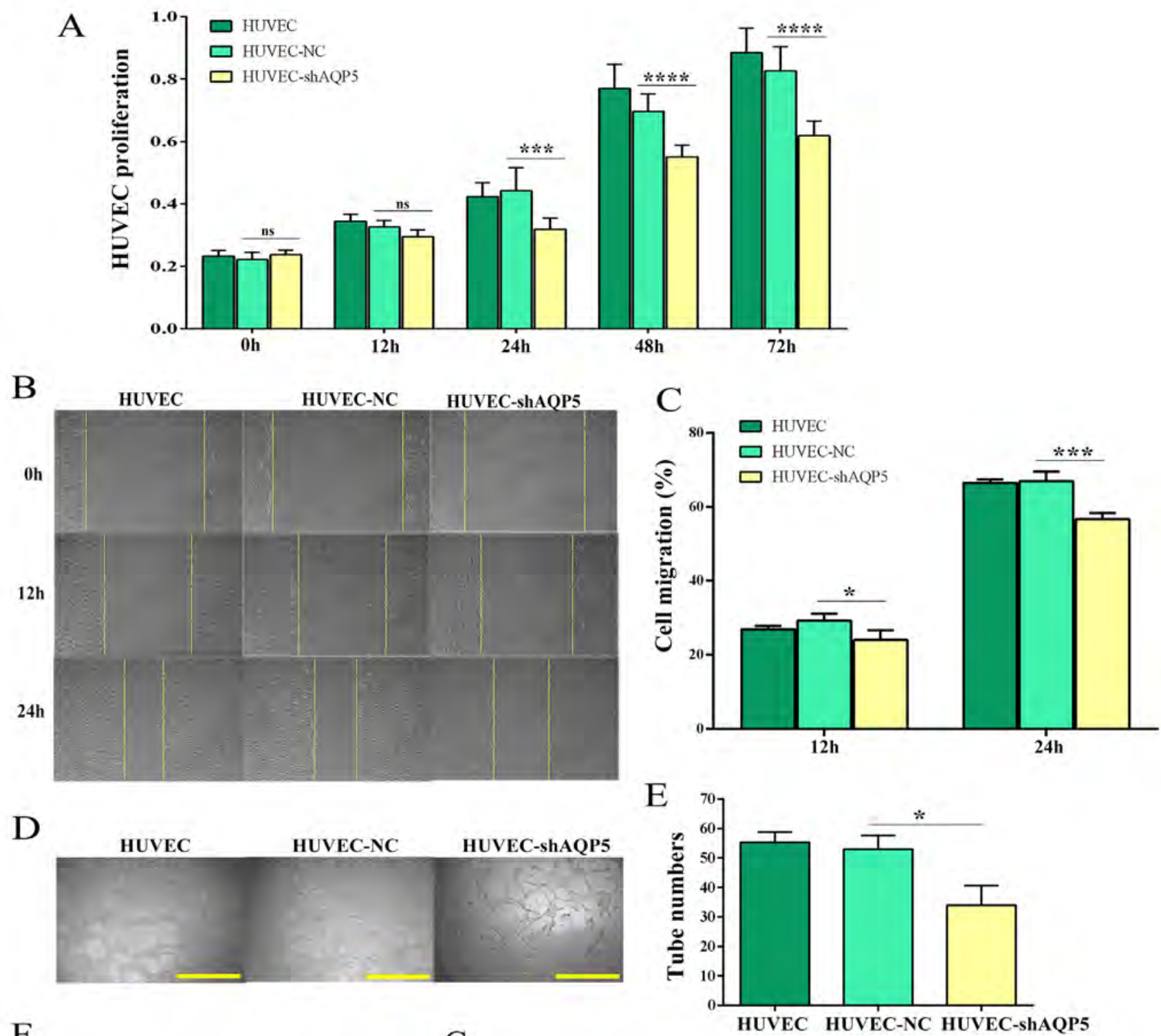

$\mathrm{F}$

G

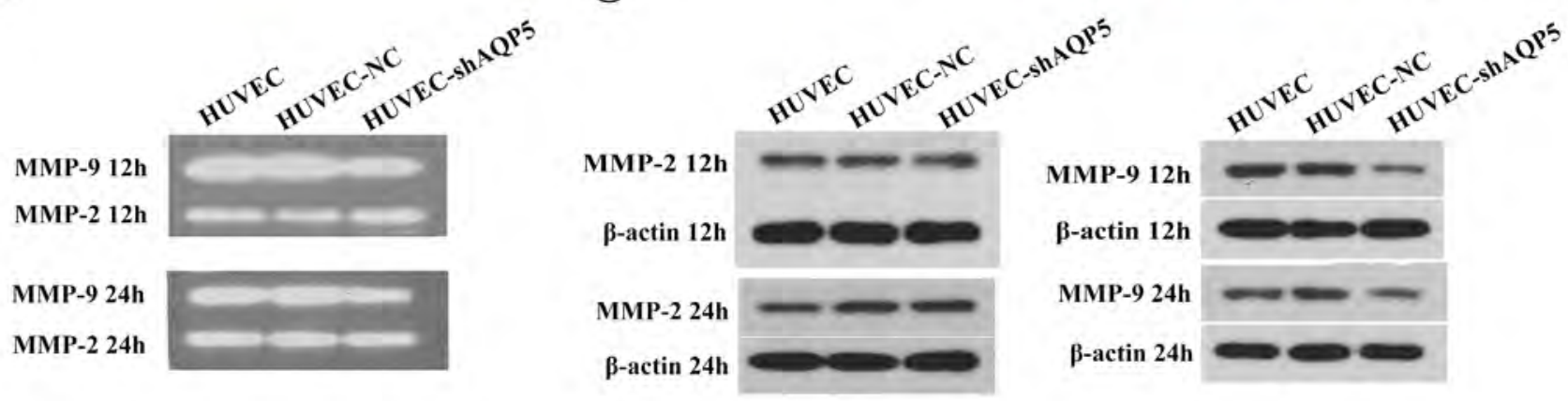

Figure 1. AQP5-shRNA inhibited the proliferation, migration and angiogenesis of HUVECs. (A) The cell proliferation was detected at $0,12,24,48$ and $72 \mathrm{~h}$. (B) The migration distance of the cells to close the scratch area was photographed at 0,12 and $24 \mathrm{~h}$. The borders of cells were marked with dashed lines. (C) Showed quantified results from (B). (D) Tube formation was photographed. Scale bar, $500 \mu \mathrm{m}$. (E) Showed quantified results from (D). Each experiment was run in triplicate and the bars represent the standard deviation. ${ }^{\star} \mathrm{p}<0.05,{ }^{* * *} \mathrm{p}<0.001,{ }^{* * * *} \mathrm{p}<0.0001$ versus $\mathrm{NC}$ group. (F) The activities and (G) expression levels of MMP-2 and MMP-9 were determined by gelatin zymography and western blot, respectively. 
A

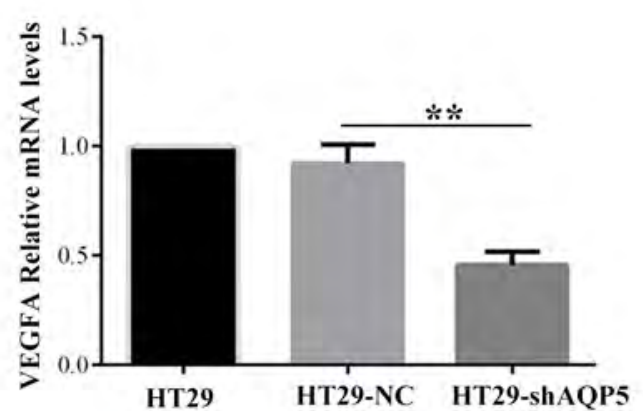

C

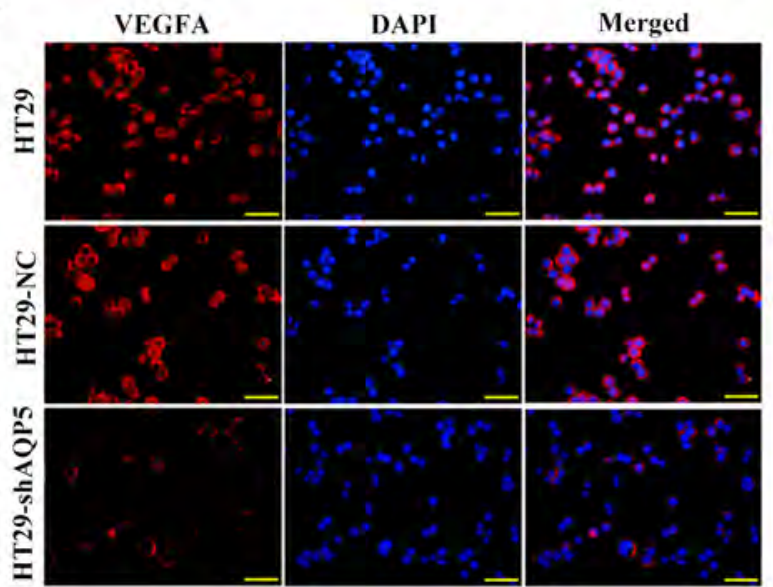

E

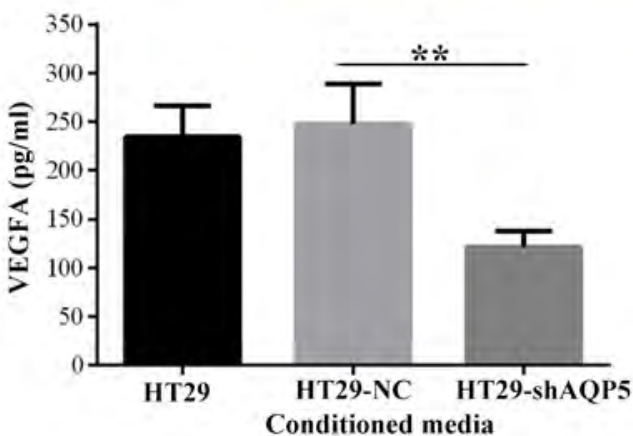

B

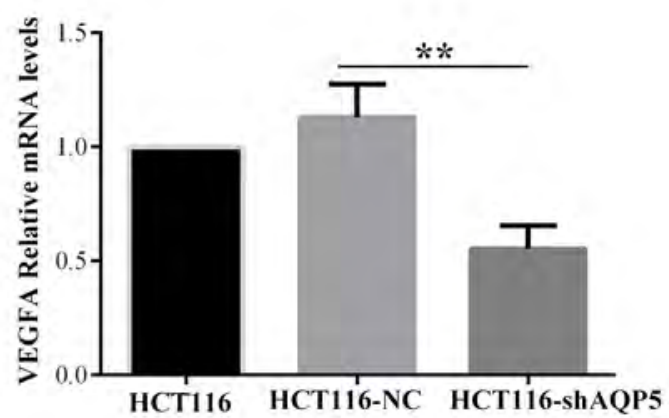

D

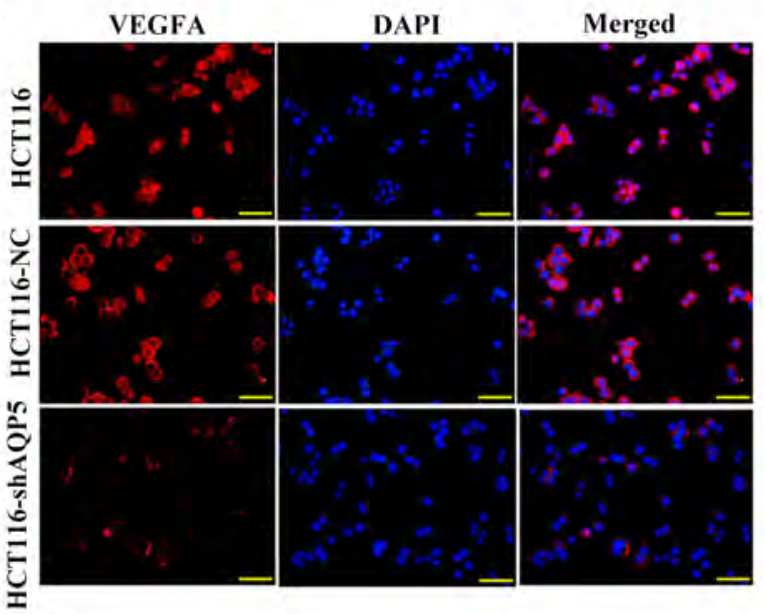

F

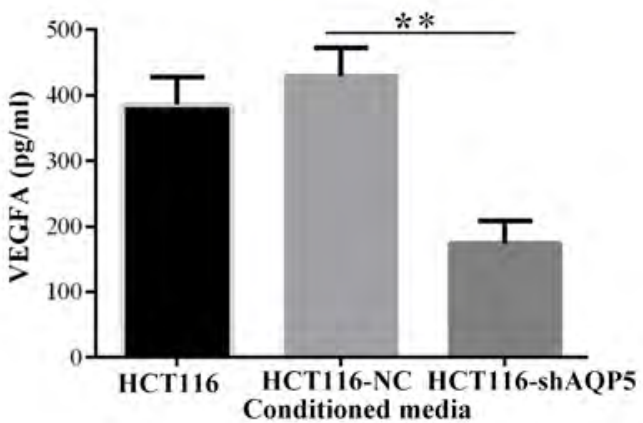

Figure 2. AQP5-shRNA decreased expression level of VEGFA in HT29 cells and HCT116 cells, and inhibited the activity of VEGFA in CM derived from HT29 and HCT116 cells. (A and B) The expression levels of VEGFA in HT29 groups and HCT116 groups were detected by qRT-PCT. The data were expressed with standard deviation. ${ }^{* *} p<0.01$ versus $N C$ group. $(C$ and $D)$ The expression levels of VEGFA in HT29 groups and HCT116 groups were detected by immunofluorescence microscopy. The red fluorescence images for AQP5 and blue images stained by DAPI for nuclei. Scale bar, $50 \mu \mathrm{m}$. (E and F) The activities of VEGFA in untreated groups, NC transfected groups and AQP5-shRNA transfected groups by Elisa assay. Each experiment was repeated in triplicate. The data were expressed with standard deviation. ${ }^{* *} \mathrm{p}<0.01$ versus $\mathrm{NC}$ group.

AQP5 shRNA inhibits the angiogenesis of xenograft tumors generated by HT29 cells. Control or shRNA-transfected HT29 cells were injected subcutaneously into nude mice, and the tumor tissues were harvested on day 30 post injection. We found that the volume of tumors generated by AQP5-silenced cancer cells was much smaller as compared to those generated by control cells (Figure 6A and B). Further, IHC results using CD31 antibody (a marker for blood vessel) illustrated that the angiogenesis of xenograft tumors was suppressed when AQP5 was knocked down (Figure 6C and D).

Expression of AQP5 in human colorectal cancer tissues. Tumor samples were additionally collected from patients with colorectal cancer to analyze the expression of AQP5. The representative IF images indicated that AQP5 was expressed both in cancer cells and CD31-positive vascular endothelial cells (Figure 7). 
A

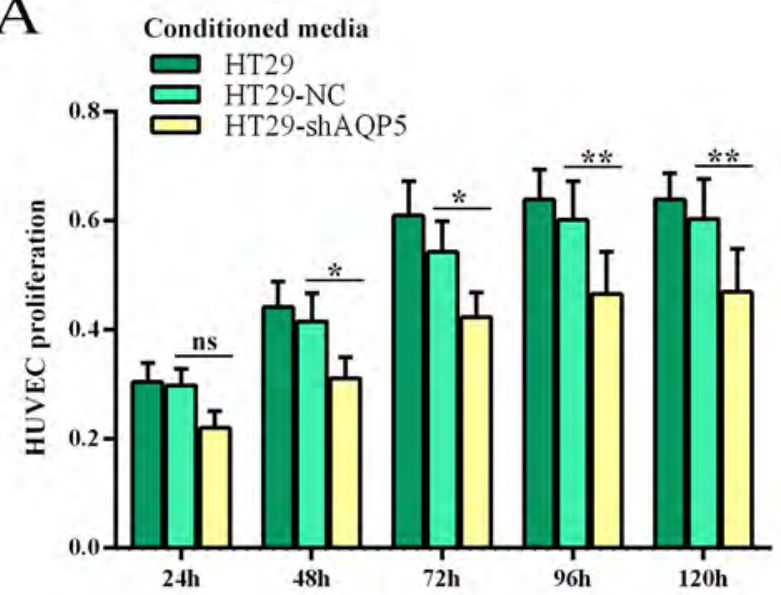

$C$

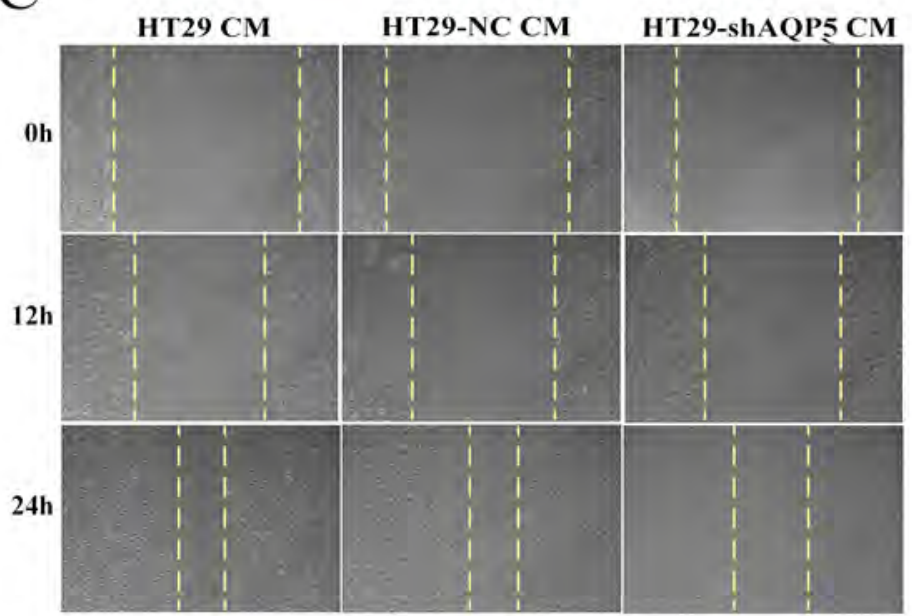

$\mathrm{E}$

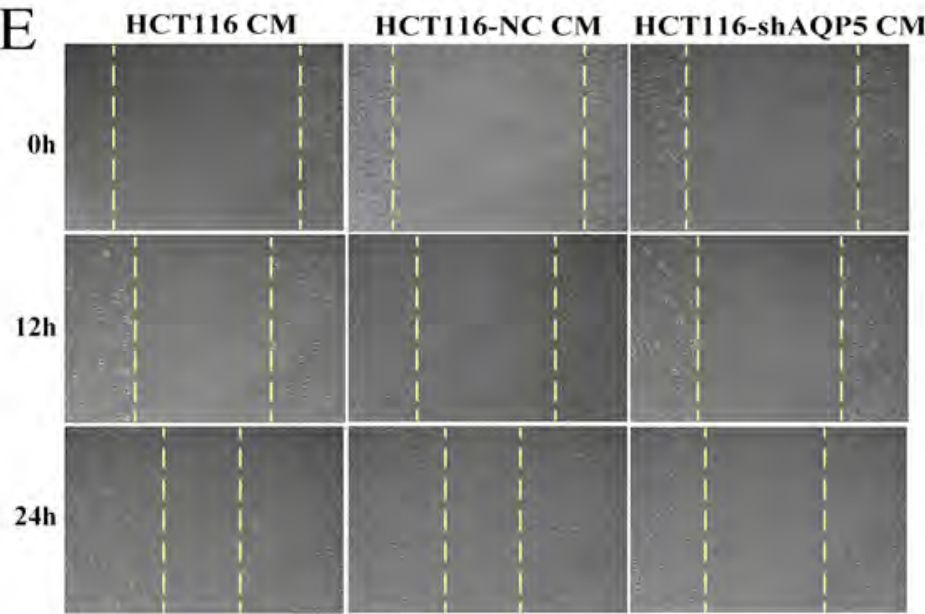

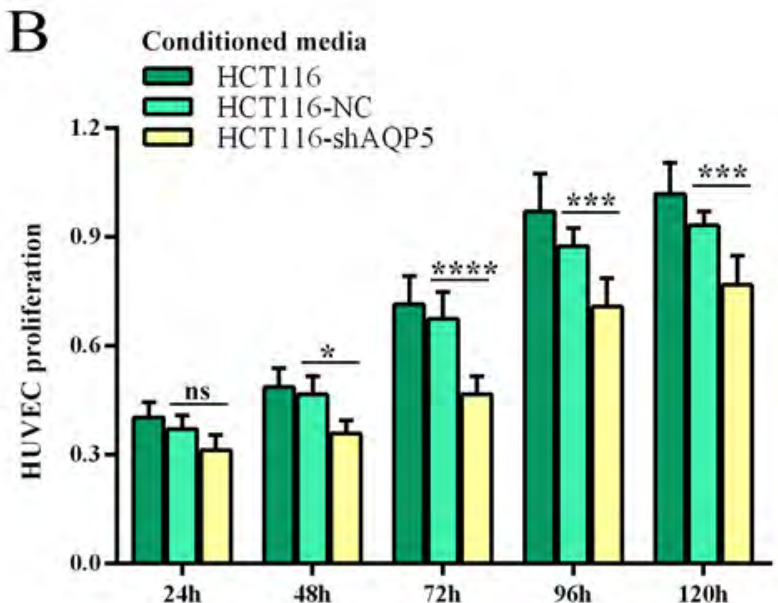

$\mathrm{D}$
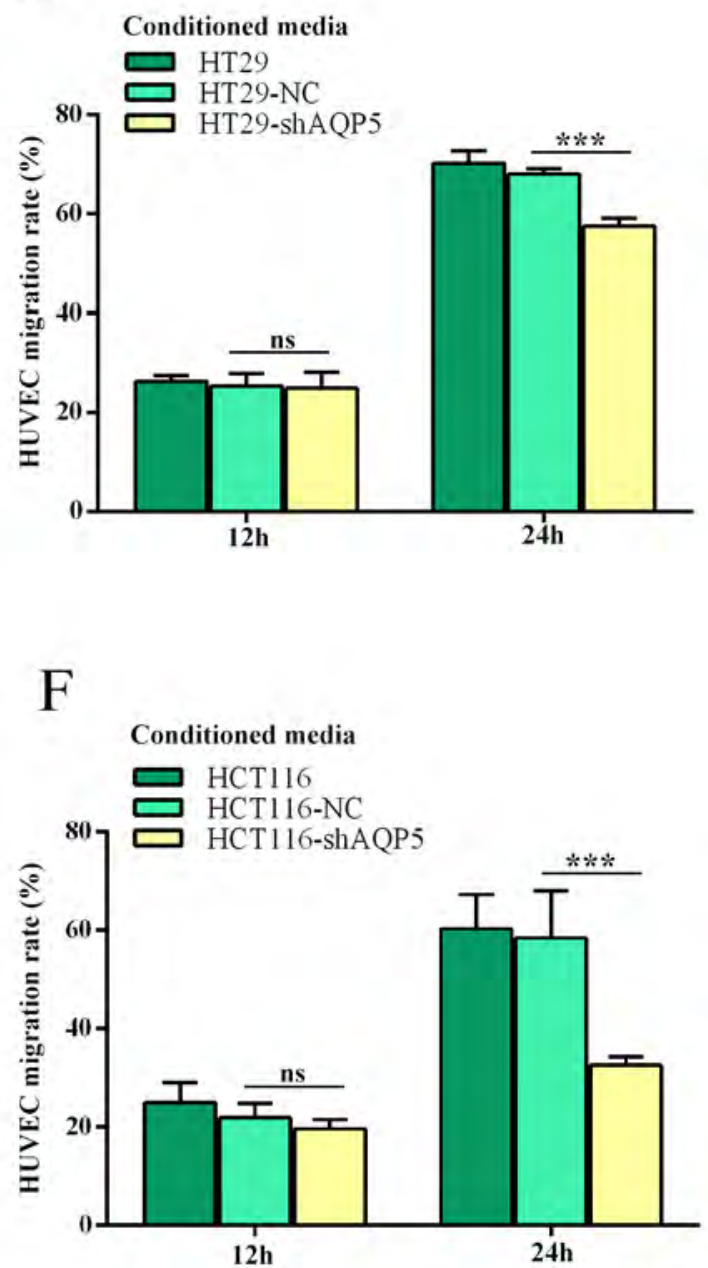

Figure 3. Effects of AQP5-shRNA on proliferation and migration of HUVECs in CM derived from HT29 and HCT116 cells. AQP5-shRNA inhibited the proliferation of HUVECs in HT29 supernatants (A) and HCT116 supernatants (B). Cell proliferation was analyzed at $24 \mathrm{~h}, 48 \mathrm{~h}, 72 \mathrm{~h}, 96 \mathrm{~h}$ and 120 $\mathrm{h}$. The migration distance of HUVECs in HT29 groups was photographed at $0 \mathrm{~h}, 12 \mathrm{~h}, 24 \mathrm{~h}(\mathrm{C})$ and the migration rate was calculated (D). The migration images (E) and migration rate (F) of HUVECs cultured in CM derived from HCT116 stable transfectants. The borders of cells were marked with dashed lines. CM: conditioned media. All experiments were run in triplicate and results were expressed as the mean \pm the standard deviation. ${ }^{\star} p<0.05$, ${ }^{* *} \mathrm{p}<0.01,{ }^{* *} \mathrm{p}<0.001,{ }^{* * *} \mathrm{p}<0.0001$ versus $\mathrm{NC}$ group. 

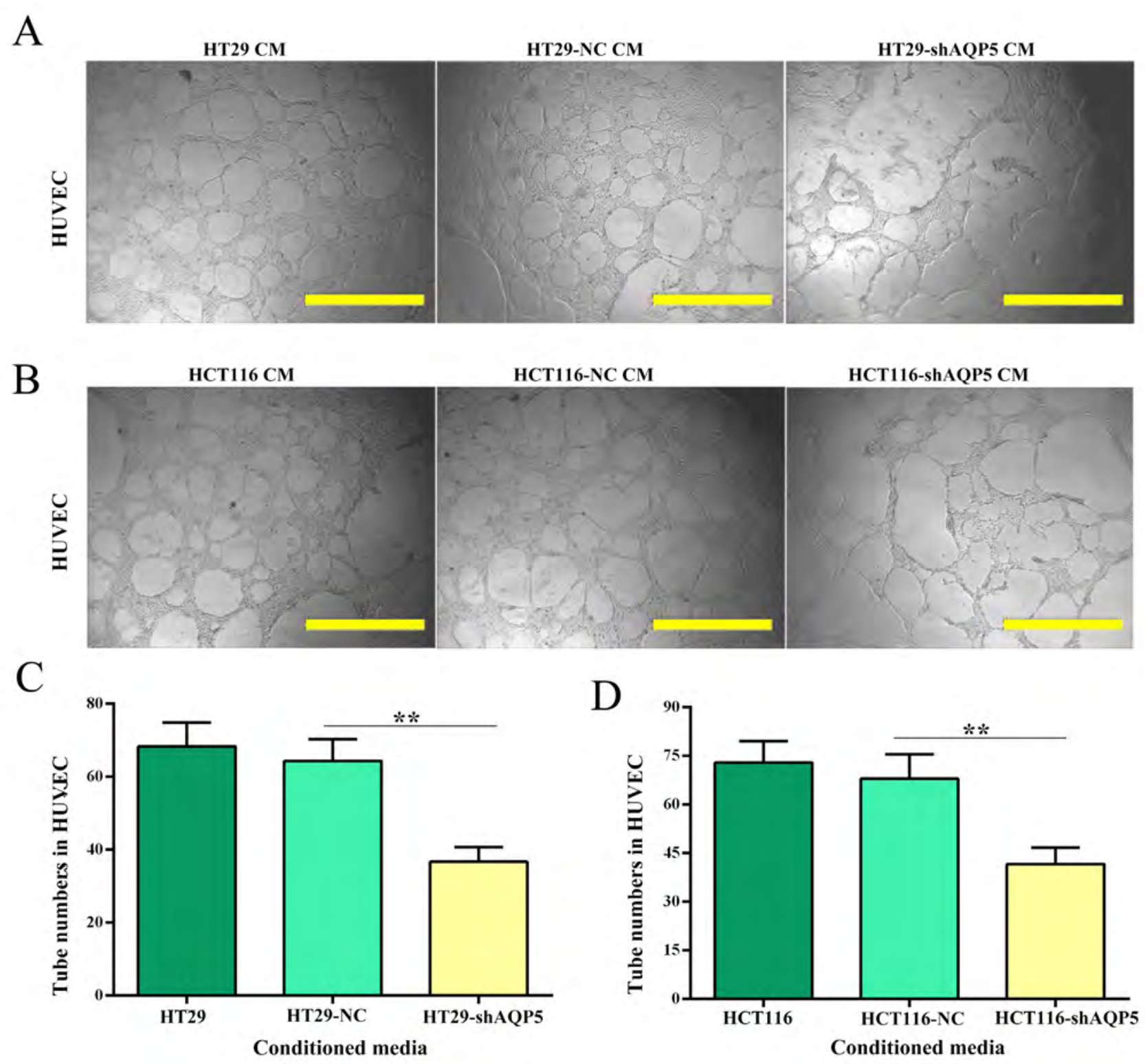

Figure 4. Effect of AQP5-shRNA on angiogenesis of HUVECs in CM derived from colorectal cancer cells. (A and B) The tube formation was photographed from untreated groups, NC transfected groups and AQP5-shRNA transfected groups. Magnification $\times 40$. Scale bar, $500 \mu \mathrm{m}$. CM: conditioned media. (C and D) Showed quantified results from (A and B), respectively. All experiments were run in triplicate and the bars represented the standard deviation. ${ }^{* *} \mathrm{p}<0.01$ versus $\mathrm{NC}$ group.

\section{Discussion}

Angiogenesis is a process controlled by molecular factors called activators and inhibitors which provides nutrients through tumor-induced capillary growth. The formation of new vessels is a turnkey event for the growth, metastasis and invasion of tumors [5]. Tumor cells continually stimulate new capillaries to grow into the tumor by releasing the tumorangiogenesis-factor (TAF). The neovascularization and growth of tumor can be prevented and can be stopped when
TAF is blocked [20]. AQP5 has been suggested as a contributor to carcinogenesis by ample previous evidence [21-23], and its abnormal overexpression was observed in colorectal cancer tissues before [24, 25]. Although AQP5 participates in the proliferation and chemosensitivity of colorectal cancer cells $[24,26]$, whether and how AQP5 affects the angiogenesis of colorectal tumor is unclear.

Given the fact that AQPs are involved in the angiogenesis of many malignant tumors [17, 27], we here investigated the role of AQP5 in colorectal cancer with a focus on angio- 
A

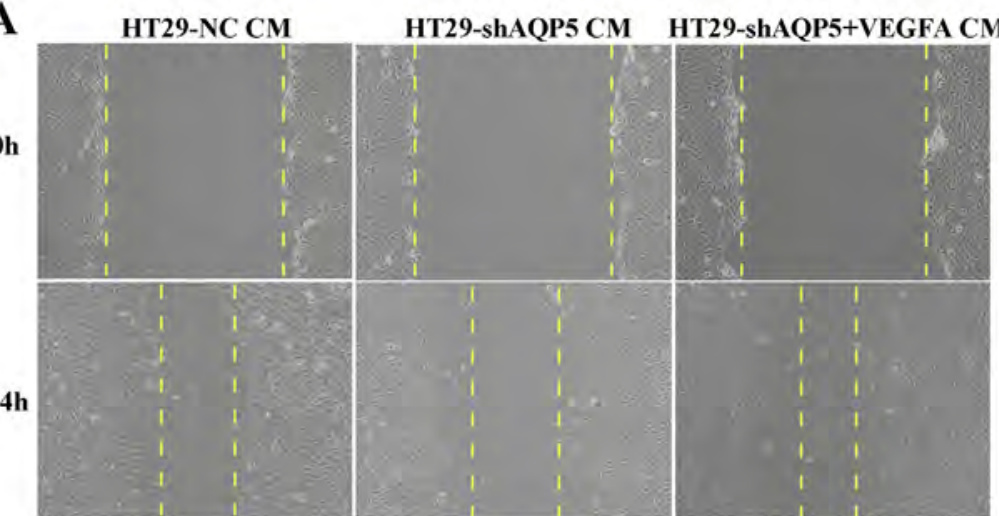

B
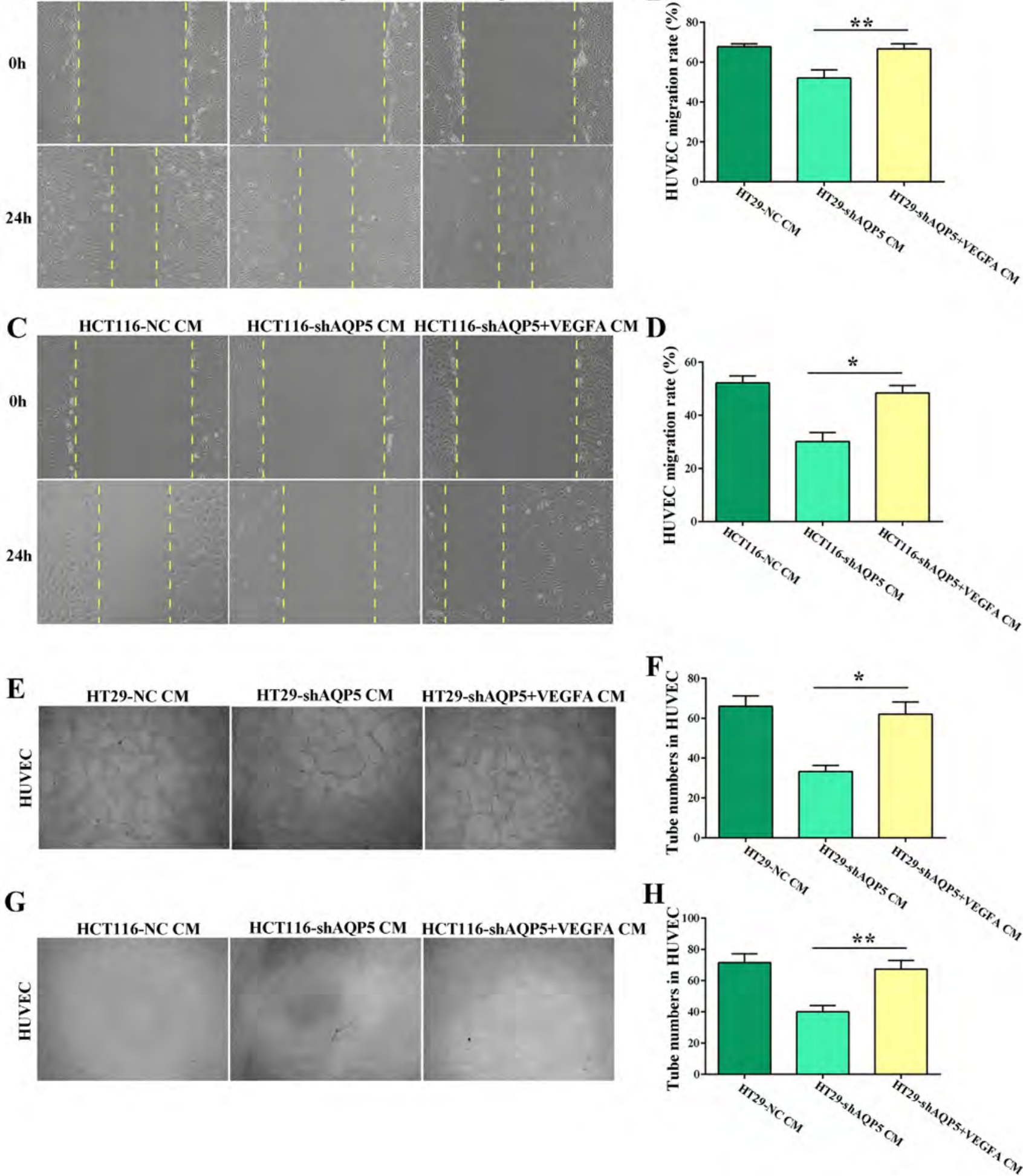

Figure 5. Addition of VEGFA protein counteracted the inhibitory effects of AQP5-shRNA on HUVEC migration and angiogenesis. (A-D) Cell migration of HUVECs cultured in CM in the presence of $10 \mathrm{ng} / \mathrm{ml}$ recombinant VEGF was enhanced, as compared to that in low-VEGF media. The borders of cells were marked with dashed lines. (E-H) Addition of VEGF partly restored the impaired angiogenic ability of HUVECs cultured in low-VEGF media. The data were expressed with standard deviation. ${ }^{*} \mathrm{p}<0.05,{ }^{* *} \mathrm{p}<0.01$ versus $A Q P 5$-shRNA treated groups. 
A
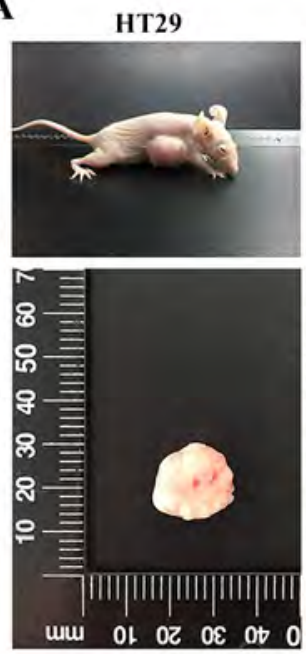

C

HT29

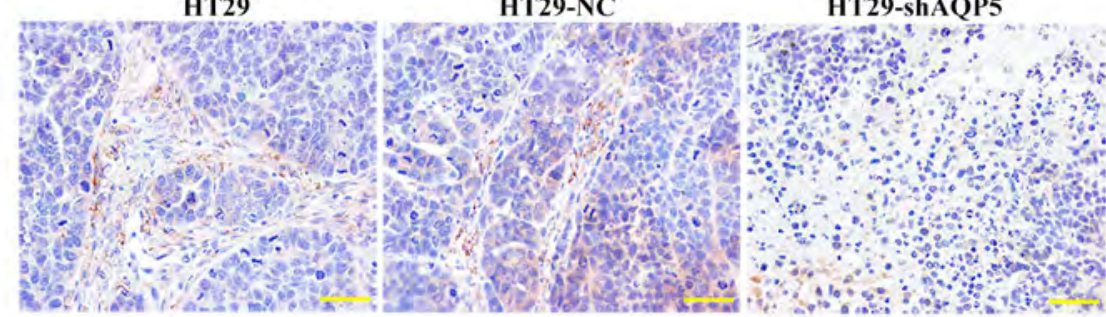

HT29-shAQP5
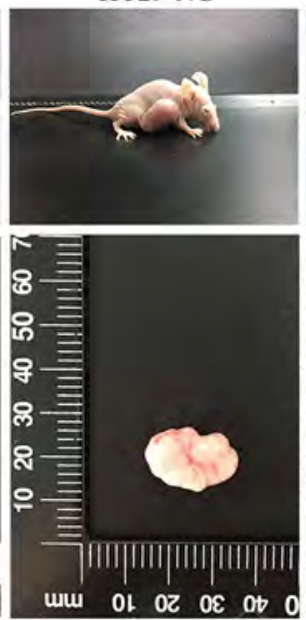

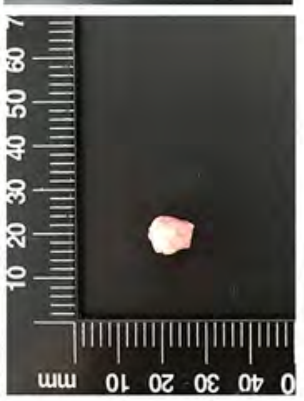

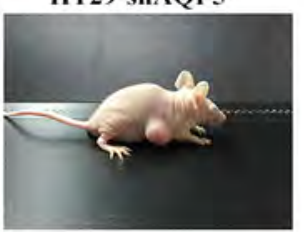

B

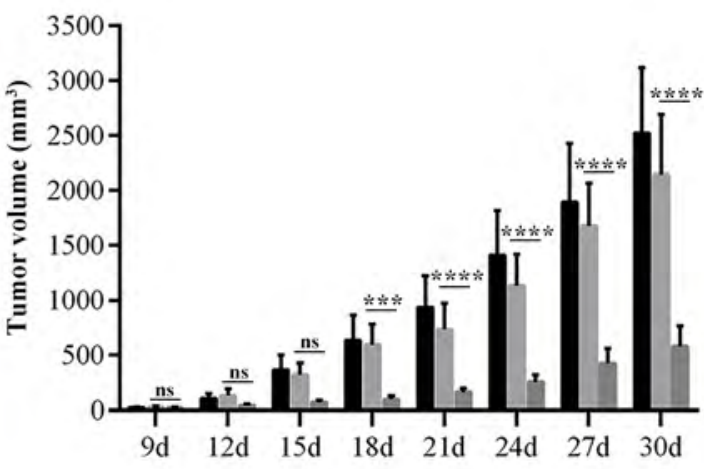

D

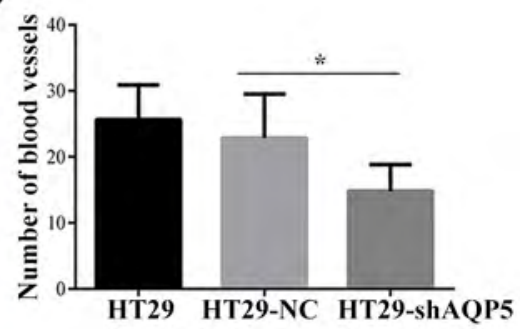

Figure 6. (A) Photographs of mice model after injection of stable HT29, HT29-NC and HT29-shAQP5 cells, and the harvested xenograft tumors were measured with vernier caliper. (B) Effect of AQP5-shRNA on tumor formation in mice model. Tumor sizes at different post-injection were much smaller in the HT29-shAQP5 group than in the HT29-NC group. (C) Immunohistochemistry was performed to detect CD31 (an endothelial marker) in the tumors. The images were visualized at $400 \times$ magnification. Scale bar, $50 \mu \mathrm{m}$. (D) The number of blood vessels was showed. All the experiments were conducted in sextuplicate and the results were expressed with standard deviation. ${ }^{\star} \mathbf{p}<0.05,{ }^{* * *} \mathbf{p}<0.001,{ }^{* * * *} \mathbf{p}<0.0001$ versus NC group.

A
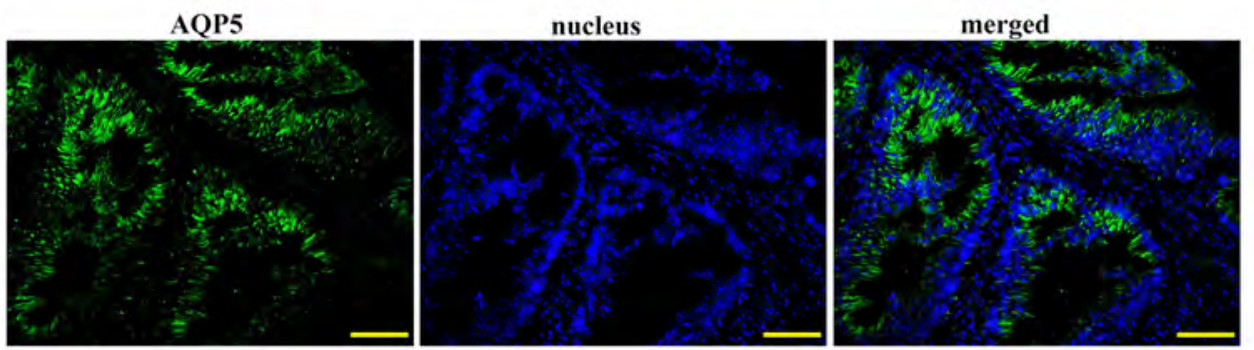

B

CD31

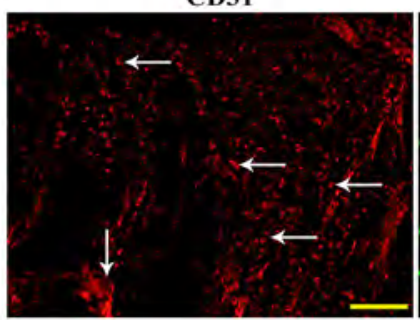

AQP5

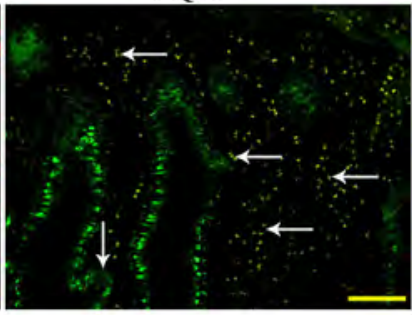

nucleus

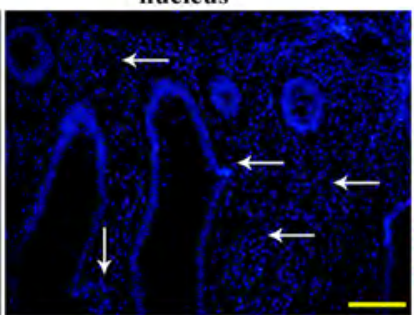

merged

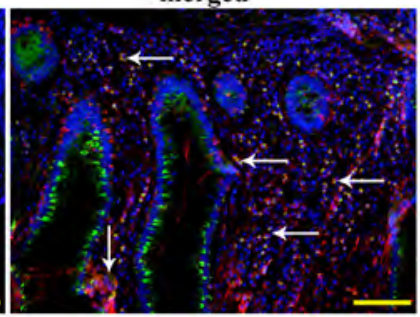

Figure 7. Expression levels of AQP5 gene and CD31 in human colorectal cancer tissues. (A) Expression of AQP5 in human colorectal cancer tissues. Nucleus was stained with DAPI. (B) Expression levels of CD31 (red) and AQP5 (green) in human colorectal cancer tissues. Nucleus was stained with DAPI. The co-localization of CD31 and AQP5 was indicated by arrows. 
genesis. We first demonstrated that knockdown of AQP5 inhibited the proliferation, migration and tube formation of HUVECs. VEGF is a multifunctional cytokine that is involved in the endothelial cell angiogenesis, migration, proliferation and survival [28]. Knockdown of AQP-1 has been reported to inhibit hypoxia-induced proliferation in human intestinal microvascular endothelial cells (HIMECs) by attenuating cobalt chloride-induced HIF-1 $\alpha$ and VEGF levels [29]. Previous work has revealed that overexpression of AQP5 prolonged HIF-2 $\alpha$ stability in a pheochromocytoma-derived cell line PC12 in chronic hypoxia, leading to the induction of VEGF, that in turn enhanced cell proliferation [30]. Hence, we speculated that AQP5 shRNA might inhibit the proliferation of HUVECs, partly via inhibition of VEGF level. MMP-2 and MMP-9 are two critical zinc-dependent proteases that promote the migration and invasion of vascular endothelial cells $[31,32]$. It is worth noting that knockdown of other AQP family members, such as AQP1 [33] and AQP3 [34], can suppress the activity of MMPs. Therefore, the activities and expressions of MMP-2 and MMP-9 were additionally detected in HUVECs in the present study. Our data showed that AQP5 shRNA inhibited the enzyme activity of MMP-9 in HUVECs without affecting the MMP-2. These findings illustrate an involvement of MMP-9 in AQP5-mediated migration of vascular endothelial cells.

VEGF is an essential pro-angiogenic factor involved in the formation of new vessels $[35,36]$ and in the pathological angiogenesis during tumor expansion [37]. Specific genetic deletion of VEGF in the endothelial lineage results in serious endothelial degeneration in mice, suggesting that the function of VEGF is mainly confined to the endothelial cells [38]. VEGFA has been shown to act via neuropilin-1 to enhance epidermal cancer stem cell survival and highly vascularized tumor formation [39]. Previous loss-of- or gain-of-function studies have demonstrated that AQP3 and AQP8 regulate the production of VEGF in non-small cell lung cancer cells [40] and leukemia cells [41]. Our current work first revealed a reduced secretion of VEGFA in AQP5-silenced HT29 and HCT116 cells. Moreover, the migratory and angiogenic ability of HUVECs were impaired when cultured in low-VEGF CM, which was partly restored by recombinant VEGF. Our results along with previous findings suggest that AQP family participate in VEGF-mediated tumor angiogenesis. In addition, tumor tissues were obtained from patients with colorectal cancer, and the expression levels of AQP5 and CD31 were detected in these samples. We found that AQP5 was abundantly expressed in both inner tumor areas and CD31-positive vessels. In xenograft tumors generated by AQP5-silenced cancer cells, the angiogenesis was suppressed. The above results indicate that AQP5 plays a role in regulating the angiogenesis of colorectal tumor at least by maintaining the generation of VEGF.

In conclusion, findings in this study reveal that the direct knockdown of AQP5 inhibits the proliferation, migration and tube formation of vascular endothelial cells and suppresses the activity and expression of MMP-9. AQP5 supports the secretion of angiogenic VEGF from colorectal cancer cells and thus contributes to the tumor angiogenesis.

Supplementary information is available in the online version of the paper.

Acknowledgments: This study was supported by grants from the Science and Technology Project of Liaoning Province (No. 2013225305) and the Foundation for President of Liaoning Medical University (No. xzjj20130233).

\section{References}

[1] SIEGEL RL, MILLER KD, JEMAL A. Cancer statistics, 2015. CA Cancer J Clin 20154; 65: 5-29. doi: 10.3322/caac.21254

[2] KINZLER KW, VOGELSTEIN B. Lessons from hereditary colorectal cancer. Cell 1996; 87: 159-170.

[3] FOLKMAN J. Toward an Understanding of Angiogenesis: Search and Discovery. Perspect Biol Med 1985; 29: 10-36.

[4] FOLKMAN J. Tumor angiogenesis. Adv Cancer Res 1985; 43: 175-203.

[5] FOLKMAN J. What is the evidence that tumors are angiogenesis dependent? J Natl Cancer Inst 1990; 82: 4-6.

[6] WALZ T, SMITH BL, AGRE P, ENGEL A. The three-dimensional structure of human erythrocyte aquaporin CHIP. EMBO J 1994; 13: 2985-2993.

[7] RAINA S, PRESTON GM, GUGGINO WB, AGRE P. Molecular cloning and characterization of an aquaporin cDNA from salivary, lacrimal, and respiratory tissues. J Biol Chem 1995; 270: 1908-1912.

[8] JO YM, PARK TI, LEE HY, JEONG JY, LEE WK. Prognostic Significance of Aquaporin 5 Expression in Non-small Cell Lung Cancer. J Pathol Transl Med 2016; 50: 122-128. doi: 10.4132/jptm.2015.10.31

[9] SALVI L, PLATEROTI P, BALDUCCI S, BOLLANTI L, CONTI FG et al. Abnormalities of retinal ganglion cell complex at optical coherence tomography in patients with type 2 diabetes: a sign of diabetic polyneuropathy, not retinopathy. J Diabetes Complicat 2016; 30: 469-476. doi: 10.1016/j.jdiacomp.2015.12.025

[10] PUST A, KYLIES D, HUBE-MAGG C, KLUTH M, MINNER $S$ et al. Aquaporin 5 expression is frequent in prostate cancer and shows a dichotomous correlation with tumor phenotype and PSA recurrence. Hum Pathol 2016; 48: 102110. doi: 10.1016/j.humpath.2015.09.026

[11] GUO XD, SUN T, YANG M, LI ZY, LI ZW et al. Prognostic value of combined aquaporin 3 and aquaporin 5 overexpression in hepatocellular carcinoma. Biomed Res Int 2013; 2013: 206525. doi: 10.1155/2013/206525

[12] SEKINE S, SHIMADA Y, NAGATA T, SAWADA S, YOSHIOKA I et al. Role of aquaporin-5 in gallbladder carcinoma. Eur Surg Res 2013; 51: 108-117. doi: 10.1159/000355675

[13] WOO J, LEE J, CHAE YK, KIM MS, BAEK JH et al. Overexpression of AQP5, a putative oncogene, promotes cell growth and transformation. Cancer Lett 2008; 264: 54-62. doi: 10.1016/j.canlet.2008.01.029 
[14] LEE SJ, CHAE YS, KIM JG, KIM WW, JUNG JH et al. AQP5 expression predicts survival in patients with early breast cancer. Ann Surg Oncol 2014; 21: 375-383. doi: 10.1245/s10434013-3317-7

[15] SHAN T, CUI X, LI W, LIN W, LI Y. AQP5: a novel biomarker that predicts poor clinical outcome in colorectal cancer. Oncol Rep 2014; 32: 1564-1570. doi: 10.3892/or.2014.3377

[16] KIM SR. Control of Granule Cell Dispersion by Natural Materials Such as Eugenol and Naringin: A Potential Therapeutic Strategy Against Temporal Lobe Epilepsy. J Med Food 2016; 19: 730-736. doi: 10.1089/jmf.2016.3712

[17] NICO B, RIBATTI D. Aquaporins in tumor growth and angiogenesis. Cancer Lett 2010; 294: 135-138. doi: 10.1016/j. canlet.2010.02.005

[18] LIVAK KJ, SCHMITTGEN TD. Analysis of relative gene expression data using real-time quantitative PCR and the 2(-Delta Delta C(T)) Method. Methods 2001; 25: 402-408.

[19] TANAKA Y, ALBELDA SM, HORGAN KJ, VAN SEVENTER GA, SHIMIZU Y. CD31 expressed on distinctive $\mathrm{T}$ cell subsets is a preferential amplifier of beta 1 integrinmediated adhesion. J Exp Med 1992; 176: 245-253.

[20] FOLKMAN J. Tumor Angiogenesis: Therapeutic Implications. N Engl J Med 1971; 285: 1182-1186. doi: 10.1056/ NEJM197111182852108

[21] ZHANG ZQ, ZHU ZX, BAI CX, CHEN ZH. Aquaporin 5 expression increases mucin production in lung adenocarcinoma. Oncol Rep 2011; 25: 1645-1650. doi: 10.3892/ or.2011.1241

[22] CHAE YK, KANG SK, KIM MS, WOO J, LEE J et al. Human AQP5 plays a role in the progression of chronic myelogenous leukemia (CML). PLoS One 2008; 3: e2594. doi: 10.1371/ journal.pone.0002594

[23] HUANG YH, ZHOU XY, WANG HM, XU H, CHEN J et al. Aquaporin 5 promotes the proliferation and migration of human gastric carcinoma cells. Tumour Biol 2013; 34: 17431751. doi: 10.1007/s13277-013-0712-4

[24] SHI X, WU S, YANG Y, TANG L, WANG Y et al. AQP5 silencing suppresses p38 MAPK signaling and improves drug resistance in colon cancer cells. Tumour Biol 2014; 35: 7035-7045. doi: 10.1007/s13277-014-1956-3

[25] WANG W, LI Q, YANG T, BAI G, LI D et al. Expression of AQP5 and AQP8 in human colorectal carcinoma and their clinical significance. World J Surg Oncol 2012; 10: 242. doi: $\underline{10.1186 / 1477-7819-10-242}$

[26] KANG SK, CHAE YK, WOO J, KIM MS, PARK JC et al. Role of human aquaporin 5 in colorectal carcinogenesis. Am J Pathol 2008; 173: 518-525. doi: 10.2353/ajpath.2008.071198

[27] VERKMAN A, HARA-CHIKUMA M, PAPADOPOULOS M. Aquaporins-new players in cancer biology. J Mol Med (Berl) 2008; 86: 523-529. doi: 10.1007/s00109-008-0303-9

[28] LEE SH, JEONG D, HAN YS, BAEK MJ. Pivotal role of vascular endothelial growth factor pathway in tumor angiogenesis. Ann Surg Treat Res 2015; 89: 1-8. doi: 10.4174/ astr.2015.89.1.1
[29] LIU B, SU X, LIU D, LI Y. Knockdown of AQP-1 restricts hypoxia-induced proliferation in human intestinal microvascular endothelial cells: role of HIF-1 alpha, VEGF and PI3K/Akt pathway. Int J Clin Exp Pathol 2016; 9: 5568-5574.

[30] GALAN-COBO A, SANCHEZ-SILVA R, SERNA A, ABREU-RODRIGUEZ I, MUNOZ-CABELLO AM et al. Cellular overexpression of aquaporins slows down the natural HIF-2alpha degradation during prolonged hypoxia. Gene 2013; 522: 18-26. doi: 10.1016/j.gene.2013.03.075

[31] AXELRAD TW, DEO DD, OTTINO P, VAN KIRK J, BAZAN NG et al. Platelet-activating factor (PAF) induces activation of matrix metalloproteinase 2 activity and vascular endothelial cell invasion and migration. FASEB J 2004; 18: 568-570.

[32] HU L, ROTH JM, BROOKS P, LUTY J, KARPATKIN S. Thrombin up-regulates cathepsin D which enhances angiogenesis, growth, and metastasis. Cancer Res 2008; 68: 46664673. doi: 10.1158/0008-5472.CAN-07-6276

[33] WEI X, DONG J. Aquaporin 1 promotes the proliferation and migration of lung cancer cell in vitro. Oncol Rep 2015; 34: 1440-1448. doi: 10.3892/or.2015.4107

[34] XIONG G, CHEN X, ZHANG Q, FANG Y, CHEN W et al. RNA interference influenced the proliferation and invasion of XWLC-05 lung cancer cells through inhibiting aquaporin 3. Biochem Biophys Res Commun 2017; 485: 627-634. doi: $\underline{10.1016 / j . b b r c .2017 .02 .013}$

[35] MAYER H, BERTRAM H, LINDENMAIER W, KORFF T, WEBERH et al. Vascular endothelial growth factor (VEGFA) expression in human mesenchymal stem cells: autocrine and paracrine role on osteoblastic and endothelial differentiation. J Cell Biochem 2005; 95: 827-839.

[36] OOMMEN S, GUPTA SK, VLAHAKIS NE. Vascular endothelial growth factor A (VEGF-A) induces endothelial and cancer cell migration through direct binding to integrin \{alpha\}9\{beta\}1: identification of a specific $\{$ alpha\}9\{beta 1 binding site. J Biol Chem 2011; 286: 1083-1092. doi: 10.1074/ jbc.M110.175158

[37] INOUE M, HAGER JH, FERRARA N, GERBER HP, HANAHAN D. VEGF-A has a critical, nonredundant role in angiogenic switching and pancreatic beta cell carcinogenesis. Cancer Cell 2002; 1: 193-202.

[38] LEE S, CHEN TT, BARBER CL, JORDAN MC, MURDOCK $\mathrm{J}$ et al. Autocrine VEGF signaling is required for vascular homeostasis. Cell 2007; 130: 691-703.

[39] GRUN D, ADHIKARY G, ECKERT RL. VEGF-A acts via neuropilin-1 to enhance epidermal cancer stem cell survival and formation of aggressive and highly vascularized tumors. Oncogene 2016; 35: 4379-4387. doi: 10.1038/onc.2015.507

[40] HOU SY, LI YP, WANG JH, YANG SL, WANG Y et al. Aquaporin-3 Inhibition Reduces the Growth of NSCLC Cells Induced by Hypoxia. Cell Physiol Biochem 2016; 38: 129-140. doi: $10.1159 / 000438615$

[41] VIECELI DALLA SEGA F, PRATA C, ZAMBONIN L, ANGELONI C, RIZZO B et al. Intracellular cysteine oxidation is modulated by aquaporin-8-mediated hydrogen peroxide channeling in leukaemia cells. Biofactors 2017; 43(2):232242. doi: $10.1002 /$ biof.1340. 
Supplementary Table 1. Main clinicopathological parameters of the colorectal carcinoma patients.

\begin{tabular}{|c|c|c|c|c|c|c|c|c|c|c|}
\hline Case & Age & $\operatorname{Sex}(F / M)$ & Primary Site & Size & Grade & Dukes staging & Differentiation & $\begin{array}{c}\text { Metastasis } \\
\text { localization }\end{array}$ & Treatment & $\begin{array}{c}\text { Adjuvant } \\
\text { treatment }\end{array}$ \\
\hline 1 & 62 & $\mathrm{~F}$ & Rectum & $3.5 \mathrm{~cm}$ & II & T3N0 & Moderate & Paraproctium & Surgery & No \\
\hline 2 & 29 & $\mathrm{~F}$ & Rectum & $5 \mathrm{~cm}$ & II & T3N0 & Moderate & Subserous layer & Surgery & No \\
\hline 3 & 64 & M & Rectum & $4.5 \mathrm{~cm}$ & II & T3N0 & Moderate & Paraproctium & Surgery & No \\
\hline 4 & 74 & M & Rectum & $3 \mathrm{~cm}$ & II & T3N0 & Moderate & Paraproctium & Surgery & No \\
\hline 5 & 66 & $\mathrm{~F}$ & Rectum & $4.5 \mathrm{~cm}$ & II & T3N0 & Moderate & Subserous layer & Surgery & No \\
\hline 6 & 48 & M & Sigmoid colon & $7.5 \mathrm{~cm}$ & II & T2N0 & Moderate & Muscular layer & Surgery & No \\
\hline 7 & 65 & $\mathrm{~F}$ & Colon & $4.5 \mathrm{~cm}$ & II & T3N0 & Moderate & Subserous layer & Surgery & No \\
\hline 8 & 75 & M & Right hemicolon & $3.5 \mathrm{~cm}$ & IIIb & T3N2a & Poor & Subserous layer & Surgery & No \\
\hline 9 & 66 & M & Colon & $4 \mathrm{~cm}$ & IIIb & $\mathrm{T} 3 \mathrm{~N} 2 \mathrm{a}$ & Moderate & Subserous layer & Surgery & No \\
\hline
\end{tabular}

A

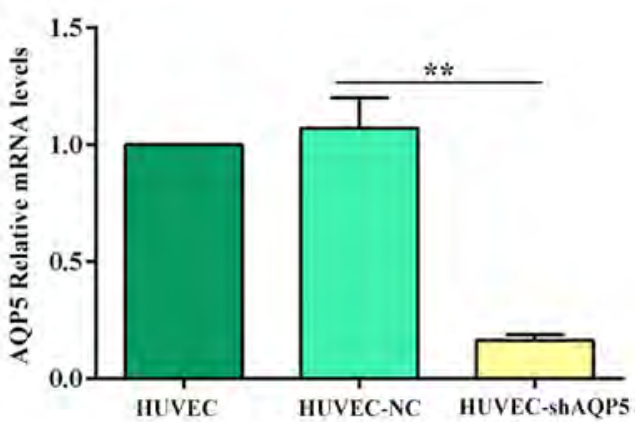

B

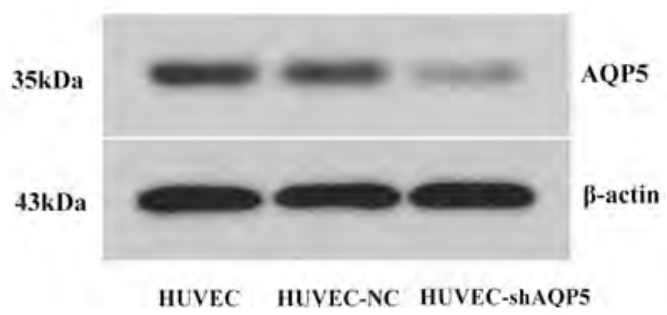

Supplementary Figure 1. ShRNA-mediated knockdown of AQP5 expression in HUVECs was detected by RT-PCR (A) and western blot (B). The results were expressed with standard deviation. ${ }^{* *} \mathrm{p}<0.01$ versus NC group.

A

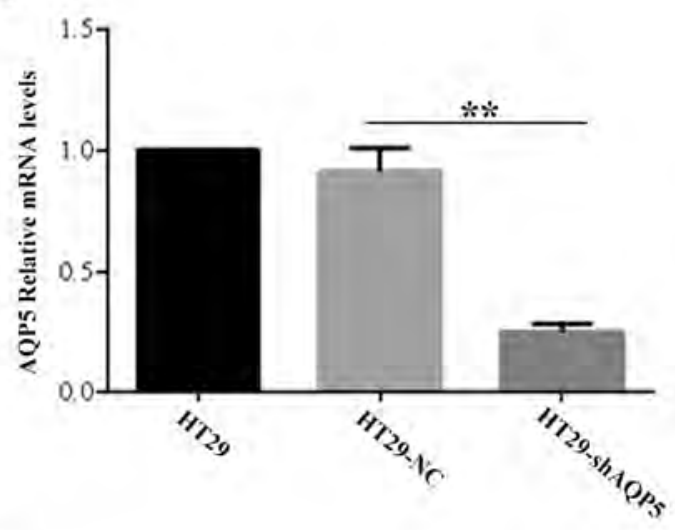

C

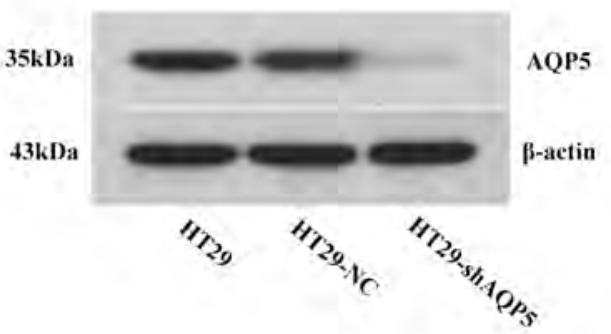

B

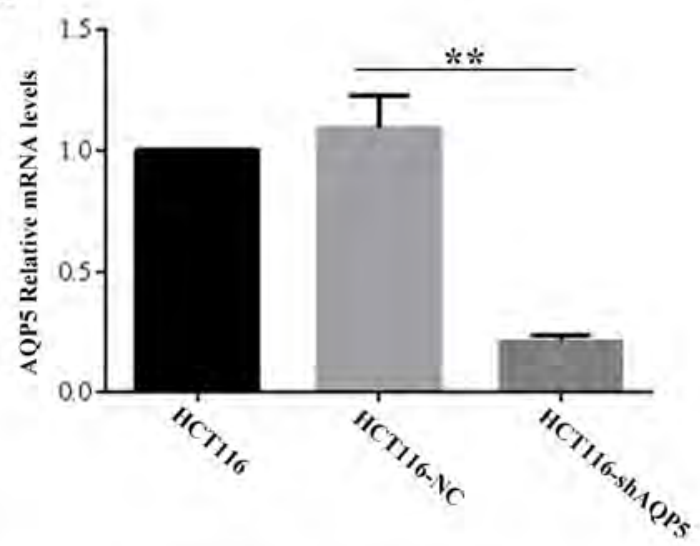

D

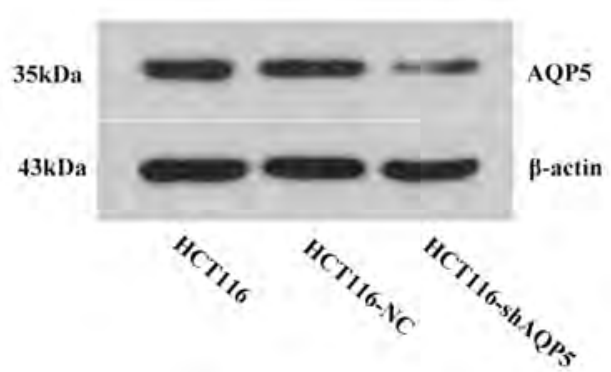

Supplementary Figure 2. ShRNA-mediated knockdown of AQP5 expression levels in HT29 and HCT116 colorectal cancer cells. RT-PCR for detection of the AQP5 expression in HT29 groups (A) and HCT116 groups (B). Each sample was run in triplicate and bars represented the standard deviation. ${ }^{* *} \mathrm{p}<0.01$ versus NC group. Western blotting detecting the expression levels of AQP5 in HT29 groups (C) and HCT116 groups (D). 